\title{
Cartilage proteoglycans
}

\author{
Assembly with hyaluronate and link protein as studied by electron microscopy
}

\author{
Matthias MÖRGELIN,* Mats PAULSSON,* Timothy E. HARDINGHAM, $\dagger$ Dick HEINEGÅD \\ and Jürgen ENGEL*§ \\ *Abteilung Biophysikalische Chemie, Biozentrum, CH-4056 Basel, Switzerland, †Division of Biochemistry, Kennedy Institute, \\ London W6 7DW, U.K., and †Department of Physiological Chemistry, University of Lund, P.O. Box 94, \\ S-22100 Lund, Sweden
}

\begin{abstract}
Aggregates formed by the interaction of cartilage proteoglycan monomers and fragments thereof with hyaluronate were studied by electron microscopy by use of rotary shadowing [Wiedemann, Paulsson, Timpl, Engel \& Heinegård (1984) Biochem. J. 224, 331-333]. The differences in shape and packing of the proteins bound along the hyaluronate strand in aggregates formed in the presence and in the absence of link protein were examined in detail. The high resolution of the method allowed examination of the involvement in hyaluronate binding of the globular core-protein domains G1, G2 and G3 [Wiedemann, Paulsson, Timpl, Engel \& Heinegård (1984) Biochem. J. 224, 331-333; Paulsson, Mörgelin, Wiedemann, Beardmore-Gray, Dunham, Hardingham, Heinegård, Timpl \& Engel (1987) Biochem. J. 245, 763-772]. Fragments comprising the globular hyaluronate-binding region G1 form complexes with hyaluronate with an appearance of necklace-like structures, statistically interspaced by free hyaluronate strands. The closest centre-to-centre distance found between adjacent G1 domains was $12 \mathrm{~nm}$. Another fragment comprising the binding region G1 and the adjacent second globular domain G2 attaches to hyaluronate only by one globule. Also, the core protein obtained by chondroitinase digestion of proteoglycan monomer binds only by domain $\mathrm{Gl}$, with domain G3 furthest removed from the hyaluronate. Globule G1 shows a statistical distribution along the hyaluronate strands. In contrast, when link protein is added, binding is no longer random, but instead uninterrupted densely packed aggregates are formed.
\end{abstract}

\section{INTRODUCTION}

Proteoglycans are a family of large complex macromolecules abundant in the extracellular matrix of all connective tissues, but also present at cell surfaces. Each proteoglycan consists of a protein core, which is substituted with the characteristic glycosaminoglycan chains and often also with shorter oligosaccharide structures (for reviews see Heinegård \& Paulsson, 1984; Hardingham, 1986). The major proteoglycan in hyaline cartilage is a high- $M_{\mathrm{r}}$ aggregating species $\left(M_{\mathrm{r}}\right.$ $1 \times 10^{6}-4 \times 10^{6}$ ) with a large extended core protein to which typically about 100 chondroitin sulphate chains, 30 keratan sulphate chains and about 60 short oligosaccharides are attached (Hascall \& Sajdera, 1970; Heinegård \& Hascall, 1974; Heinegård \& Axelsson, 1977; Lohmander et al., 1980; Heinegård et al., 1985).

Aggregates are formed by the non-covalent interaction between a hyaluronate-binding region of the protein core and a decasaccharide segment of a hyaluronate, which is a long unbranched polymer (Hardingham \& Muir, 1972; Hascall \& Heinegård, 1974). The interaction is stabilized by the additional binding of a link protein (Heinegård \& Hascall, 1974; Hardingham, 1979), which has affinity for both the binding region of the proteoglycan and the hyaluronate to which it is attached (Franzén et al., 1981; Tengblad, 1981), such that a ternary complex is formed between these three components (Bonnet et al., 1985). Many proteoglycans may bind to each hyaluronate chain and form aggregates with a length of as much as $4000 \mathrm{~nm}$ and a diameter of 500-600 nm (for reviews see Heinegård \& Paulsson, 1984; Hardingham, 1986).

Analysis of proteoglycan structure by electron microscopy was introduced by Rosenberg et al. (1970) and by Wellauer et al. (1972). Cartilage proteoglycans were prepared for electron microscopy by spreading with cytochrome $c$ at a water/air interface as originally designed by Kleinschmidt et al. (1962) for nucleic acids, followed by negative staining with uranyl acetate or rotary shadowing with heavy metals. This method primarily allowed studies of the distribution of sidechain substituents along the protein core. Protein domains within the core were first resolved by rotary shadowing of proteoglycans sprayed on to mica (Wiedemann et al., 1984). Three globular domains (G1, G2 and G3) and two extended regions (E1 and E2) can be distinguished (Paulsson et al., 1987). G1 is located at the $N$-terminus and is separated from $\mathbf{G} 2$ by strand E1 $(25 \mathrm{~nm})$. It is followed by strand E2 $(280 \mathrm{~nm})$, which is terminated by $\mathrm{G} 3$, which forms the $C$-terminus of the protein core. G3 was present in only a proportion of proteoglycans isolated from cartilage, which may result from its removal during a slow extracellular proteolytic attack (Heinegård et al., 1986; Paulsson et al., 1987). The $N$-terminal globe $\mathrm{Gl}$ can be correlated with the hyaluronate-binding region, and the long extended region E2 with the chondroitin sulphate-rich region of the protein core (Paulsson et al., 1987). The observation of globe G3 agrees well with the demonstration by

$\S$ To whom correspondence and requests for reprints should be addressed. 
cDNA sequencing that the core protein contains a $C$ terminal region devoid of glycosaminoglycan-attachment sites and with a structure stabilized by disulphide bridges (Doege et al., 1986; Sai et al., 1986; Oldberg et al., 1987).

In the present work we have investigated the participation of the different domains in the binding to hyaluronate. The structures of the aggregates formed with hyaluronate by proteoglycan monomers and various fragments derived from them were rendered observable by spraying sample/glycerol mixtures and rotary metal shadowing. In particular, the influence of link protein on the structure and mode of binding was studied.

\section{MATERIALS AND METHODS}

\section{Cartilage proteoglycan components and fragments thereof}

Materials for the isolation of proteoglycan components from pig laryngeal cartilage were as described by Bonnet et al. (1985) and from rat chondrosarcoma and bovine nasal-septal cartilage as described by Heinegård et al. (1985). Methods for the preparation of proteoglycan monomers, fragments thereof and link protein were as described by Paulsson et al. (1987). The hyaluronate used was a high- $M_{\mathrm{r}}$ form (Healon, Pharmacia, Uppsala, Sweden) prepared from rooster comb.

\section{Reconstitution of link-free complexes}

Hyaluronate-binding region was mixed with hyaluronate in $0.2 \mathrm{M}-\mathrm{NH}_{4} \mathrm{HCO}_{3}, \mathrm{pH} 7.9$ (associative conditions, final concentrations $20-200 \mu \mathrm{g} / \mathrm{ml}$ and $4 \mu \mathrm{g} / \mathrm{ml}$ respectively), and allowed to react for several hours at room temperature. The double-globe fragment (G1-E1-G2; Paulsson et al., 1987) was dialysed overnight at $4^{\circ} \mathrm{C}$ against $4 \mathrm{M}$-guanidinium chloride/0.2 $\mathrm{M}-\mathrm{NH}_{4} \mathrm{HCO}_{3}$, pH 7.9 (dissociative conditions), to remove contaminating short hyaluronate oligosaccharides. After addition of hyaluronate, the mixture was dialysed in a special dialysis apparatus designed for small volumes (5-50 $\mu \mathrm{l}$; Biowerk, Basel, Switzerland) for 2 days at $4^{\circ} \mathrm{C}$ against $0.2 \mathrm{M}-\mathrm{NH}_{4} \mathrm{HCO}_{3}$, pH 7.9. Double-globe fragment and hyaluronate concentrations were $100-200 \mu \mathrm{g} / \mathrm{ml}$ and 2-3 $\mu \mathrm{g} / \mathrm{ml}$ respectively. Chondroitinase-treated monomer $(200-400 \mu \mathrm{g} / \mathrm{ml})$ and hyaluronate $(3-4 \mu \mathrm{g} / \mathrm{ml})$ were mixed in $0.2 \mathrm{M}-\mathrm{NH}_{4} \mathrm{HCO}_{3}, \mathrm{pH} 7.9$, and allowed to react for several hours at room temperature.

\section{Reconstitution of link-stabilized aggregates}

Proteoglycan monomers $(2 \mathrm{mg} / \mathrm{ml})$ and proteolytic fragments thereof $(20-400 \mu \mathrm{g} / \mathrm{ml})$ were dialysed overnight at $4^{\circ} \mathrm{C}$ against $4 \mathrm{M}$-guanidinium chloride/ $0.2 \mathrm{M}-\mathrm{NH}_{4} \mathrm{HCO}_{3}, \mathrm{pH}$ 7.9. After addition of hyaluronate $(2-5 \mu \mathrm{g} / \mathrm{ml})$ and link protein $(50-150 \mu \mathrm{g} / \mathrm{ml})$, both dissolved in the same solvent, the mixtures were dialysed against $0.2 \mathrm{M}-\mathrm{NH}_{4} \mathrm{HCO}_{3}, \mathrm{pH} 7.9$, for 2 days at $4^{\circ} \mathrm{C}$ and either frozen or immediately prepared for electron microscopy.

\section{Electron microscopy}

Glycerol spraying/metal rotary shadowing and electron microscopy were by previously described protocols (Shotton et al., 1979; Engel \& Furthmayr, 1987). Samples were diluted into $0.2 \mathrm{M}-\mathrm{NH}_{4} \mathrm{HCO}_{3}, \mathrm{pH} 7.9$, shortly before use. The dilute solutions (aggregate concentration $20-200 \mu \mathrm{g} / \mathrm{ml}$ ) were mixed $1: 1$ with $80 \%$ (v/v) glycerol and immediately sprayed on to freshly cleaved mica pieces from a distance of about $20 \mathrm{~cm}$. The samples were then brought into the vacuum chamber of a Balzers BAF 301 freeze-etching apparatus and dried for $5 \mathrm{~h}$ under high vacuum, followed by rotary shadowing with platinum/carbon at a $9^{\circ}$ angle and coated with carbon at $90^{\circ}$. The replicas were floated on to distilled water and picked up on 400-mesh copper grids. Specimens were viewed at $80 \mathrm{kV}$ in a Zeiss 109 transmission electron microscope. The magnification was calibrated by photography of a calibration grid (Balzers, Liechtenstein) under the same electron-optical conditions.

\section{RESULTS}

\section{Reconstitution of complexes between isolated binding region and hyaluronate in the presence and in the absence of link protein}

Hyaluronate-binding region and link protein were prepared by size-exclusion chromatography in the presence of $4 \mathrm{M}$-guanidinium chloride after trypsin digestion of proteoglycan aggregates from bovine nasal-septal cartilage. Link-free complexes were obtained by mixing solutions of binding region and hyaluronate in $0.2 \mathrm{M}$ $\mathrm{NH}_{4} \mathrm{HCO}_{3}$, pH 7.9. For the reconstitution of linkstabilized aggregates, binding region was dialysed into dissociative conditions, i.e. $4 \mathrm{M}$-guanidinium chloride/ $0.2 \mathrm{M}-\mathrm{NH}_{4} \mathrm{HCO}_{3}, \mathrm{pH}$ 7.9. Link protein and hyaluronate, dissolved in the same buffer, were added, and the mixtures were transferred back into associative conditions by dialysis against $0.2 \mathrm{M}-\mathrm{NH}_{4} \mathrm{HCO}_{3}, \mathrm{pH}$ 7.9.

After spraying and rotary shadowing, the assembly products could be seen in the electron microscope as beaded-string structures. Fig. 1 shows selected extended link-free complexes obtained at different molar ratios of hyaluronate segments (HA) to isolated binding region (BR). The molar ratios $C_{\mathrm{BR}}^{0} / C_{\mathrm{HA}}^{0}$ ) were calculated with the assumption that a binding region $\left(M_{\mathrm{r}} 65000\right)$ requires 12 hyaluronate disaccharide units $\left(M_{\mathrm{r}} 4600\right)$. The value of 12 disaccharide units corresponds to the minimum distance between binding regions of $12 \mathrm{~nm}$ (see below), assuming an extended conformation of hyaluronate in the binding region-hyaluronate complex (Arnott \& Mitra, 1984). The hyaluronate concentration was constant in these experiments, and the total concentration of hyaluronate segments, thus calculated, amounts to $C_{\mathrm{HA}}^{0}=0.87 \mu \mathrm{M}$. Without addition of binding region, various forms of aggregation among hyaluronate strands were consistently observed in electron micrographs (results not shown). These networks and other possible hyaluronate self-assembly forms are largely disrupted at binding region/hyaluronate ratios exceeding $0.17: 1$, demonstrating that binding region efficiently prevents self-association of hyaluronate. Instead, large fields of single thin hyaluronate strands with globular binding regions attached like beads on a string are revealed. The lengths of the complexes range from about $100 \mathrm{~nm}$ to several micrometres, depending on the source and thereby the $M_{\mathrm{r}}$ of the hyaluronate. Between the beads the faint strand of unoccupied hyaluronate is visible (arrows in Fig. 1). It appears from a visual inspection of Fig. 1 that, at low ratios of binding region to hyaluronate, empty and occupied regions are present. Under these conditions no clusters of binding-region globules are found. Rather, the distribution of occupied and free sites appears to be random, indicating that the binding is non-co-operative. 

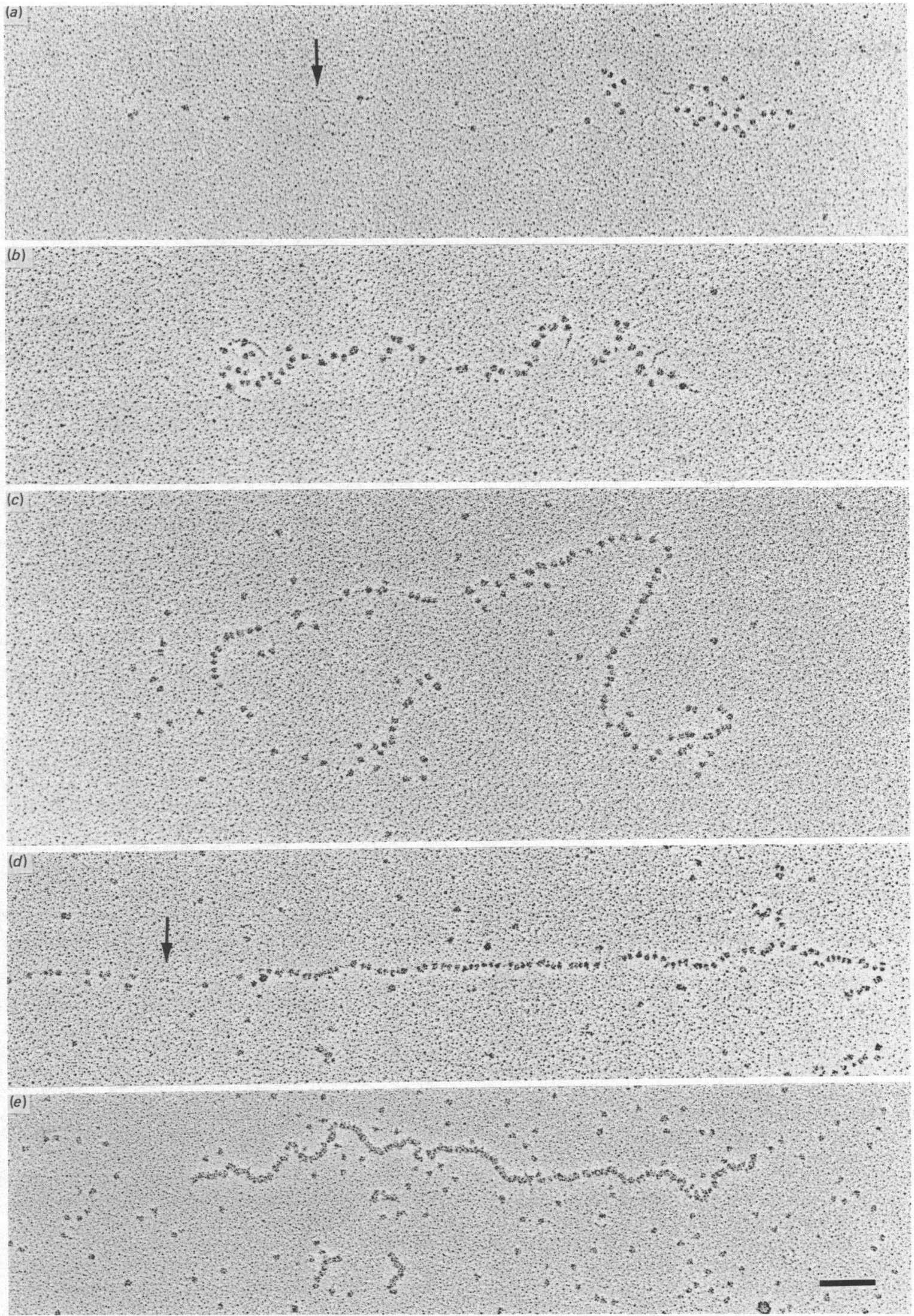

Fig. 1. Assembly products of isolated binding region with hyaluronate rendered visible by rotary shadowing

The molar ratios of binding-region fragments to hyaluronate segments (12 disaccharide units, dry weight) were $0.07: 1$ (a), $0.17: 1(b), 0.34: 1(c), 1.0: 1(d)$ and 4.8:1 (e). Free strands of hyaluronate are clearly visible (arrows). The bar represents $100 \mathrm{~nm}$.

Vol. 253 


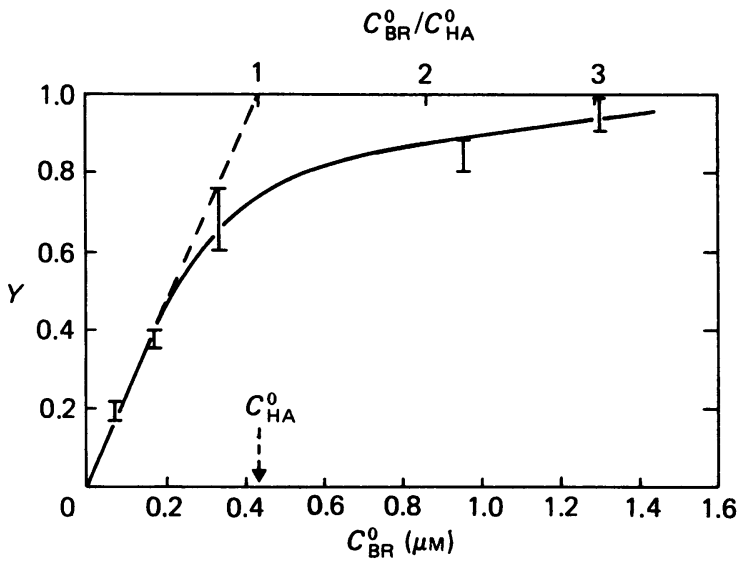

Fig. 2. Degrees of saturation $Y$ of hyaluronate with bindingregion fragment as a function of total concentration of binding-region $C_{\mathrm{BR}}^{0}$

Values of $Y$ were evaluated from electron micrographs, of which selected examples are shown in Fig. 1. Error bars correspond to standard deviations of evaluations from five to ten separate electron-microscopic fields. The total accessible hyaluronate concentration was evaluated from an extrapolation of the initial slope of the binding curve.

Only at high ratios of binding region to hyaluronate is an almost continuous chain of globules visible with only short interruptions of free hyaluronate (arrow in Fig. 1d). Furthermore, when the ratios of binding region to hyaluronate increase, the presence of unbound binding region is manifested by an increasing number of globules visible in the areas of the fields surrounding the binding region-hyaluronate complexes. Interestingly, the background of unaggregated binding region extends over the whole area of each sprayed drop, whereas particles complexed with hyaluronate can be observed mainly in a distinct region near the border of the drops, as with all other aggregate preparations.

For quantification of these 'titration experiments' monitored by electron microscopy, the sum $L_{0}$ of the length of 10-20 well-resolved binding region-hyaluronate complexes were measured at a given binding region/ hyaluronate ratio. The total number $N$ of globules attached to these hyaluronate strands was counted, and the fractional degree of saturation $Y=N \cdot l / L_{0}$ was calculated. Here $l=12 \mathrm{~nm}$ is assumed (see below) for the length of a hyaluronate segment that is covered by a single binding-region fragment. $Y$ is plotted in Fig. 2 as a function of the total concentration of binding region $\left(C_{\mathrm{BR}}^{0}\right)$ at a constant total hyaluronate concentration $C_{\mathrm{HA}}^{0}$. From the extrapolation of the initial slope of this curve is obtained a value of $C_{\mathrm{HA}}^{0}=0.43 \mu \mathrm{M}$, expressed in molar units of binding sites for binding region. This value is about half of that calculated from the dry weight. The difference may be explained by a fraction of hyaluronate not participating in binding owing to self-association, by the possibility that each binding region occupies a larger segment of hyaluronate than calculated for an extended chain (see the Discussion section), or by the possibility that the degree of saturation is underestimated by the electron-microscopic technique. In view of these uncertainties, the $C_{\mathrm{BR}}^{0} / C_{\mathrm{HA}}^{0}$ ratios calculated on the basis of dry weights should be considered as upper limits, and true values may be larger by a factor of 2 -fold. A rough

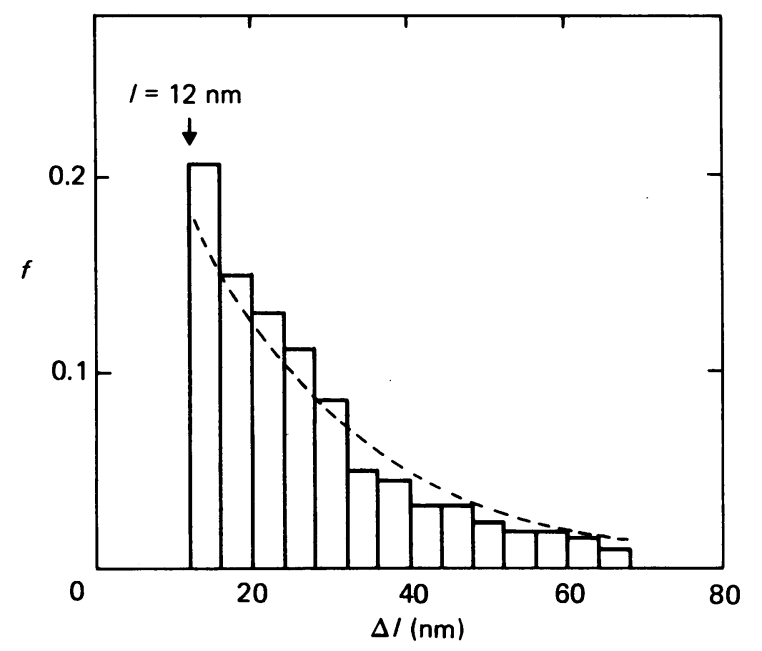

Fig. 3. Histogram of the distances between globules of binding region bound to hyaluronate strands

A total of 550 distances was measured for 20 hyaluronate strands (for one example see Fig. $1 b$ ) at a $C_{\mathrm{BR}}^{0} / C_{\mathrm{HA}}^{0}$ ratio of 0.07: 1 . The fraction $f$ of globules with a distance of $l$ to its nearest neighbour (measured along the contour of the hyaluronate strand) is plotted in intervals of $4 \mathrm{~nm}$. The closest distance between adjacent globules is $l=12 \mathrm{~nm}$. The dashed curve indicates the theoretical dependence for random binding (see the text).

estimate of the dissociation equilibrium constant $K_{\mathrm{D}}$ may be obtained from the binding curve shown in Fig. 2. $K_{\mathrm{D}}=C_{\mathrm{HA}}^{0}(1-Y)^{2} / Y$ at the point $C_{\mathrm{HA}}^{0}=C_{\mathrm{BR}}^{0}$ for a simple non-co-operative binding equilibrium, ignoring possible effects of overlapping binding sites (McGhee \& Von Hippel, 1974). With $Y=0.75$ we obtain $K_{\mathrm{D}}=4 \times 10^{-8} \mathrm{M}$, a value in good agreement with constants for the binding determined by other procedures, i.e. $2.5 \times 10^{-8} \mathrm{M}$ (Nieduszynski et al., 1980; Nieduszynski \& Sheehan, 1981), $2 \times 10^{-8}$ м (Cleland, 1979), $5.6 \times 10^{-8} \mathrm{M}$ (Christner et al., 1978) and $7.7 \times 10^{-8} \mathrm{M}$ (Tengblad, 1981).

For a quantitative evaluation of the statistics of binding, the distances between neighbouring globules were measured on a given $C_{\mathrm{BR}}^{0} / C_{\mathrm{HA}}^{\mathrm{o}}$ ratio of $0.17: 1$. A histogram of the distances is shown in Fig. 3. About $20 \%$ of the globules approached their neighbours to a centre-to-centre distance of $12-16 \mathrm{~nm} ; 12 \mathrm{~nm}$ is the closest distance observed and is most likely caused by direct sterical contact of two globules. An interval width of $4 \mathrm{~nm}$ was chosen for the histogram, which also reflects the resolution of the length measurements. The fraction $W_{\mathrm{u}}=0.83$ of unoccupied $4 \mathrm{~nm}$-long segments of hyaluronate and the fraction of bound sites $W_{\mathrm{b}}=0.17$ were determined by counting the number of occupied sites and by measuring the length of free hyaluronate. This theoretical dependence (dashed curve in Fig. 3) was obtained by assuming a random occurrence of occupied and unoccupied sites. The probability of binding-region particles in direct contact $(n=0)$ or separated by a gap of $n \times 4 \mathrm{~nm}(n=1,2,3 \ldots)$ is then given by $W_{\mathrm{b}}{ }^{2} W_{\mathrm{u}}{ }^{n}$. The sum of all possible states is $W_{\mathrm{b}}{ }^{2}\left(1+W_{\mathrm{u}}+W_{\mathrm{u}}{ }^{\mathrm{u}}+\right.$ $\left.W_{\mathrm{u}}{ }^{3}+\ldots\right)=W_{\mathrm{b}}$ and consequently the corresponding fractions (dashed curve in Fig. 3) are given by $W_{\mathrm{b}} W_{\mathrm{u}}{ }^{n}$.

The structure of the aggregates is dramatically changed when link protein is involved in aggregate formation. Fig. 4 shows a comparison between a link-free and a 

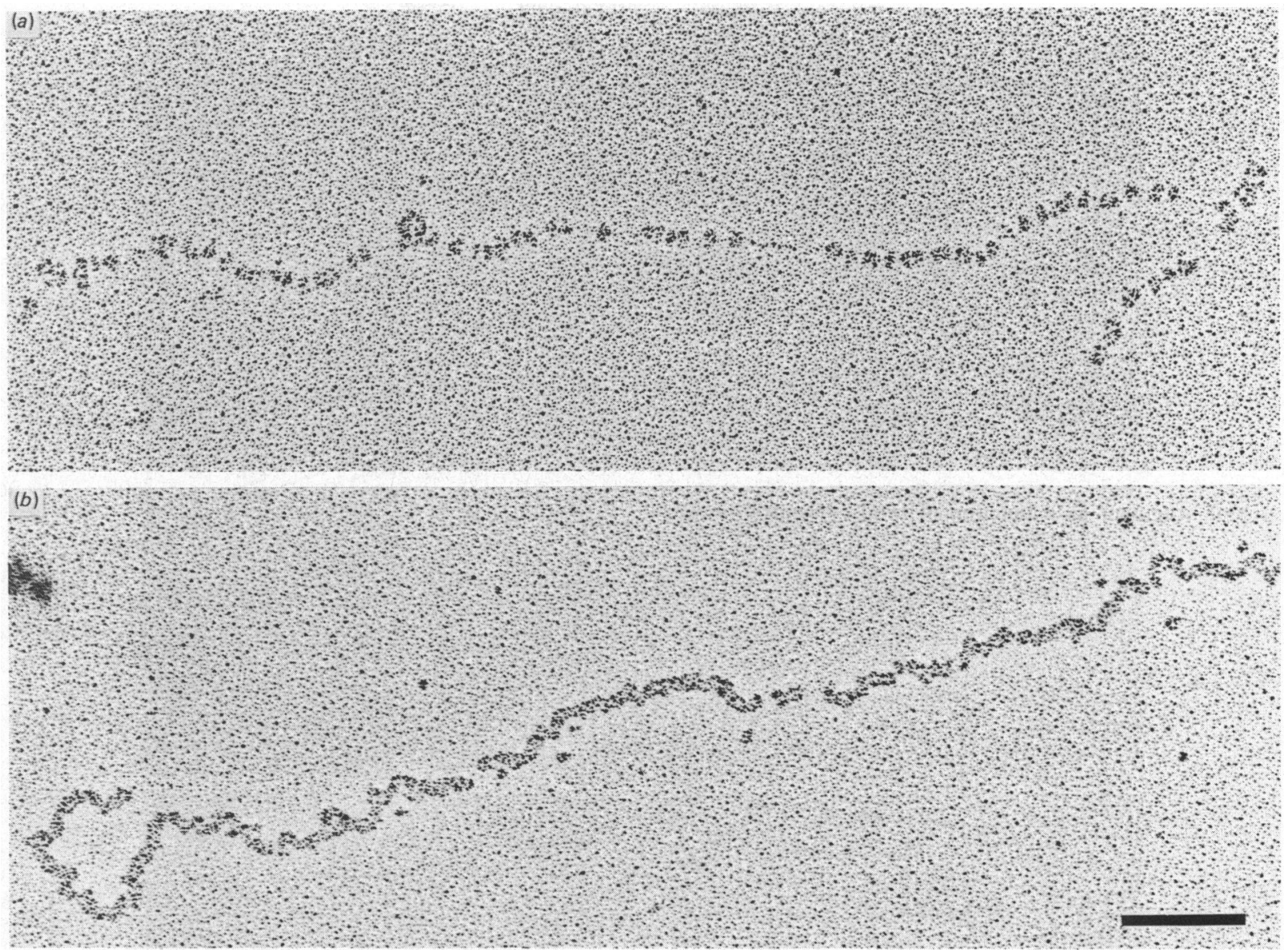

Fig. 4. Complexes of hyaluronate with binding region in the absence (a) and in the presence (b) of link protein after rotary shadowing

Molar proportions are: hyaluronate segments to binding region, $0.52: 1$, and hyaluronate segments to binding region to link protein, $0.52: 1: 3$. The bar represents $100 \mathrm{~nm}$.

link-stabilized central filament, reconstituted at a molar ratio of hyaluronate to binding-region fragment of 0.52:1 (a) and molar proportions of hyaluronate to binding-region fragment to link protein $0.52: 1: 3(b)$, i.e. proportions close to saturation values. These values were calculated from the dry weights, with $M_{\mathrm{r}}=4600, M_{\mathrm{r}}=$ 65000 and $M_{\mathrm{r}}=40000$ for hyaluronate segments, binding region and link protein respectively. Linkstabilized aggregates have a more condensed appearance as compared with aggregates without link, and single globules can no longer be resolved. Preliminary experiments with sub-stoichiometric amounts of binding region and link protein show that aggregation in the presence of link takes place in such a way that empty hyaluronate segments alternate with patches of decorated central filament, indicating co-operativity.

\section{Reconstitution of complexes between the double-globe fragment and hyaluronate in the presence and in the absence of link protein}

The double-globe fragment (domains G1-E1-G2; Paulsson et al., 1987) was isolated from pig laryngealcartilage proteoglycans by proteolysis with trypsin under mild conditions, followed by size-exclusion chromatography. Some early preparations contained large amounts of low- $M_{\mathrm{r}}$ hyaluronate fragments and required dialysis before use. They were then combined with hyaluronate or with hyaluronate and link protein and brought back into associative conditions. Large areas of long thread-like complexes, similar to those obtained by the combination of isolated binding region with hyaluronate, became apparent after rotary shadowing. Fig. 5(a) shows selected aggregates formed by the assembly of double globes with hyaluronate, at a molar ratio of hyaluronate $12 \mathrm{~nm}$ segments to double globes of $0.33: 1$. The selective interaction of only one globule with hyaluronate is clearly seen, resulting in the generation of a well-decorated central filament of binding region and hyaluronate. The second globule points out radially into the surrounding space and can be seen at a distance of about $21 \mathrm{~nm}$ away from the central filament. The same holds true for aggregates of double globes and hyaluronate formed in the presence of link protein. Fig. 5(b) shows some link-stabilized aggregates of double globes and hyaluronate. Again the interaction of hyaluronate, binding region and link protein leads to a heavily stained central filament, which consists of uninterrupted patches in which individual adjacent binding regions cannot be resolved. Sometimes the row of second globules accompanying the central strand flips from one side to the other, and then the whole complex looks like a spiral structure forced into a two-dimensional appearance. The regions of these presumed superhelical turns are indicated by arrows. Segments indicated with A and B are shown 

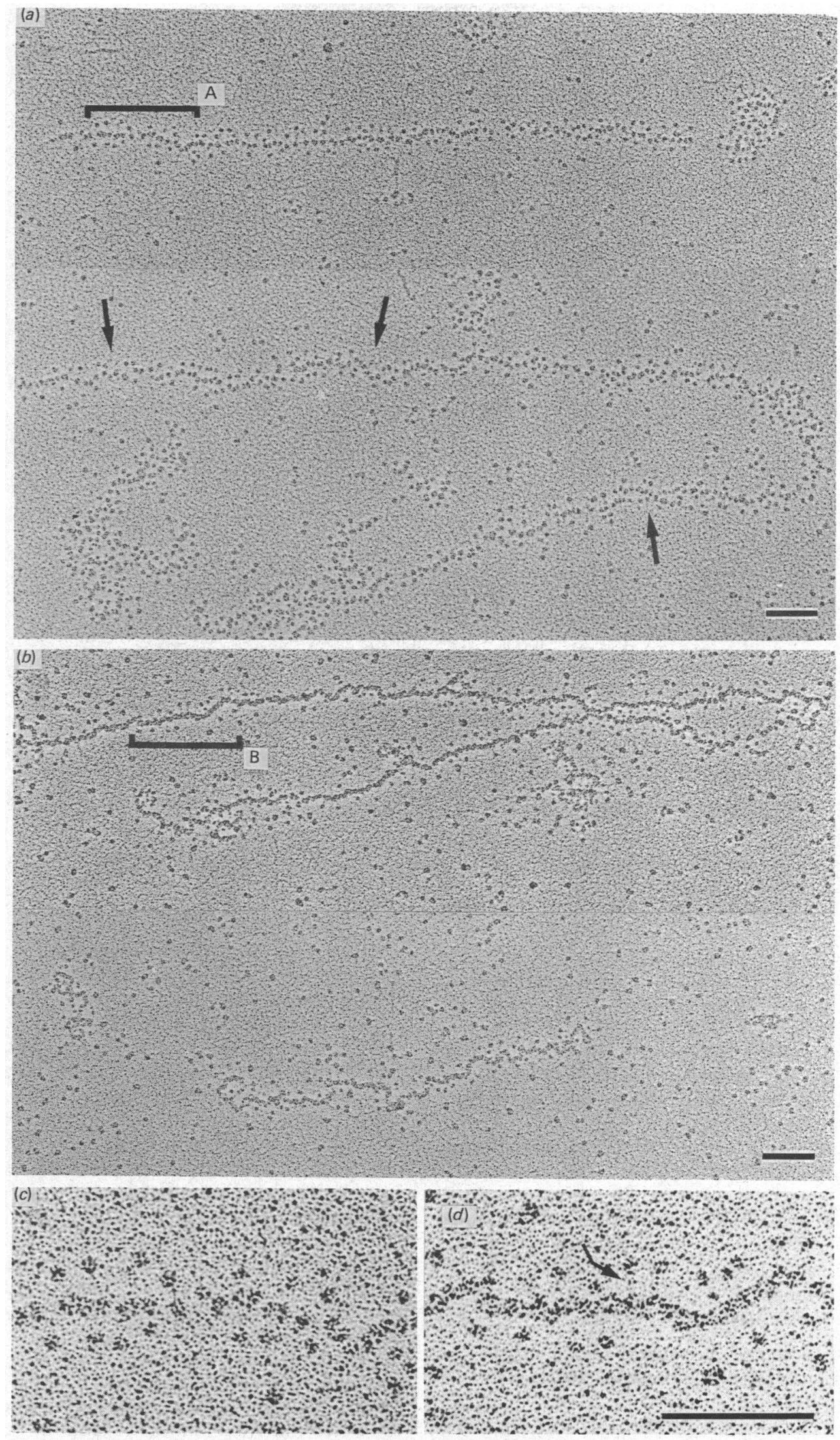

\section{Fig. 5. Assembly of double-globe fragment with hyaluronate with and without link protein}

Molar proportions are: hyaluronate segments to double globes, 0.33:1 (a), and hyaluronate segments to double globes to link protein, 0.33:1:3(b). One globule can be seen to bind to hyaluronate, and the other one points away. Possible superhelical regions in the complexes are indicated by arrows. Segments indicated by brackets A and B are shown at higher magnification in $(c)$ and $(d)$ respectively. The arrow in $(d)$ indicates the connection E1 between G1 and G2. The bars in the lower right-hand corners represent $100 \mathrm{~nm}$. 

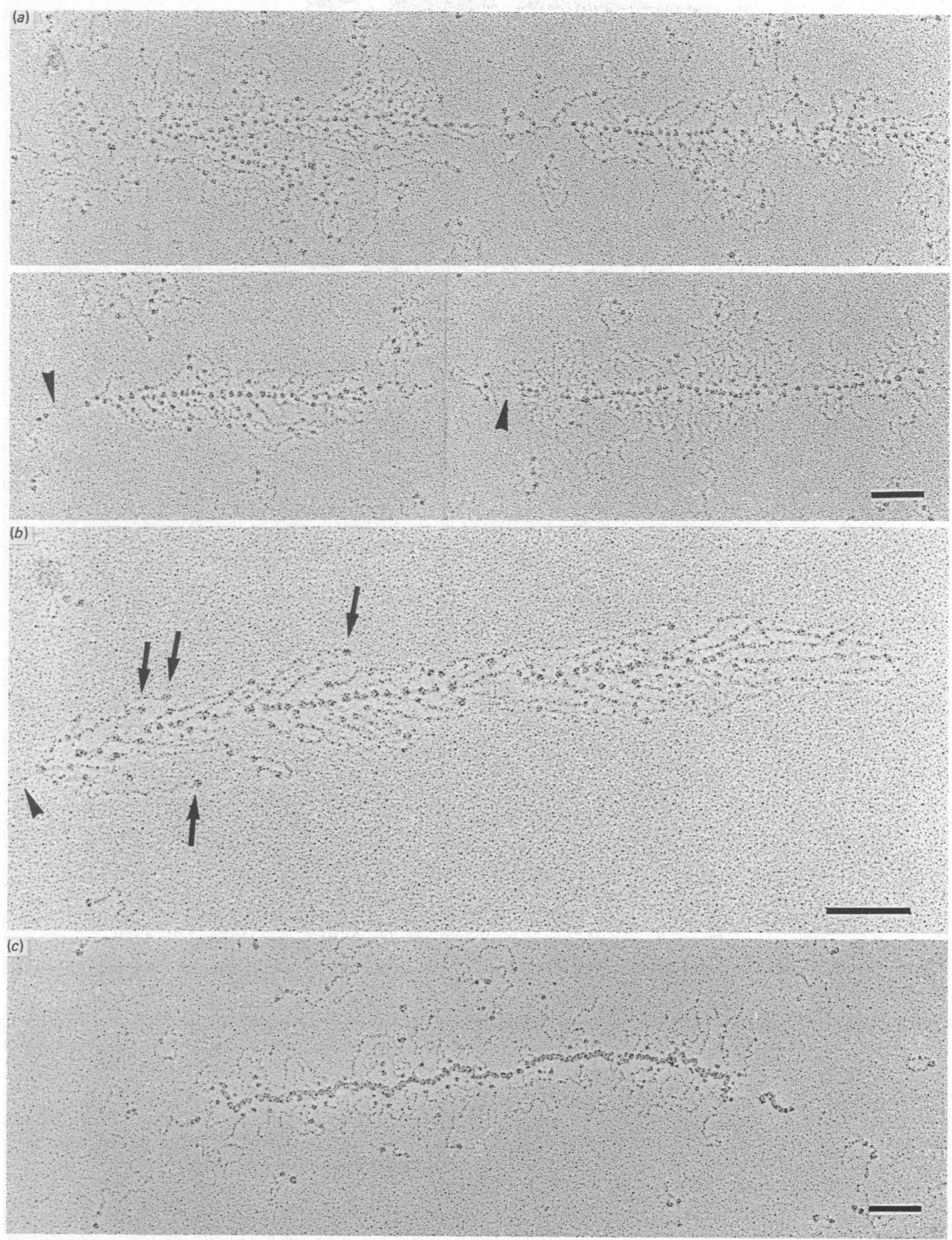

Fig. 6. Electron micrographs after rotary shadowing of $(a)$ complexes of core protein with hyaluronate at a molar ratio of hyaluronate segments to core protein $0.52: 1,(b)$ selected complex of the same material, and (c) link-stabilized aggregate formed at molar proportions of hyaluronate segments to core protein to link protein 0.52:1:3

The third globule is clearly revealed in (b) (arrows). Bars represent $100 \mathrm{~nm}$. 

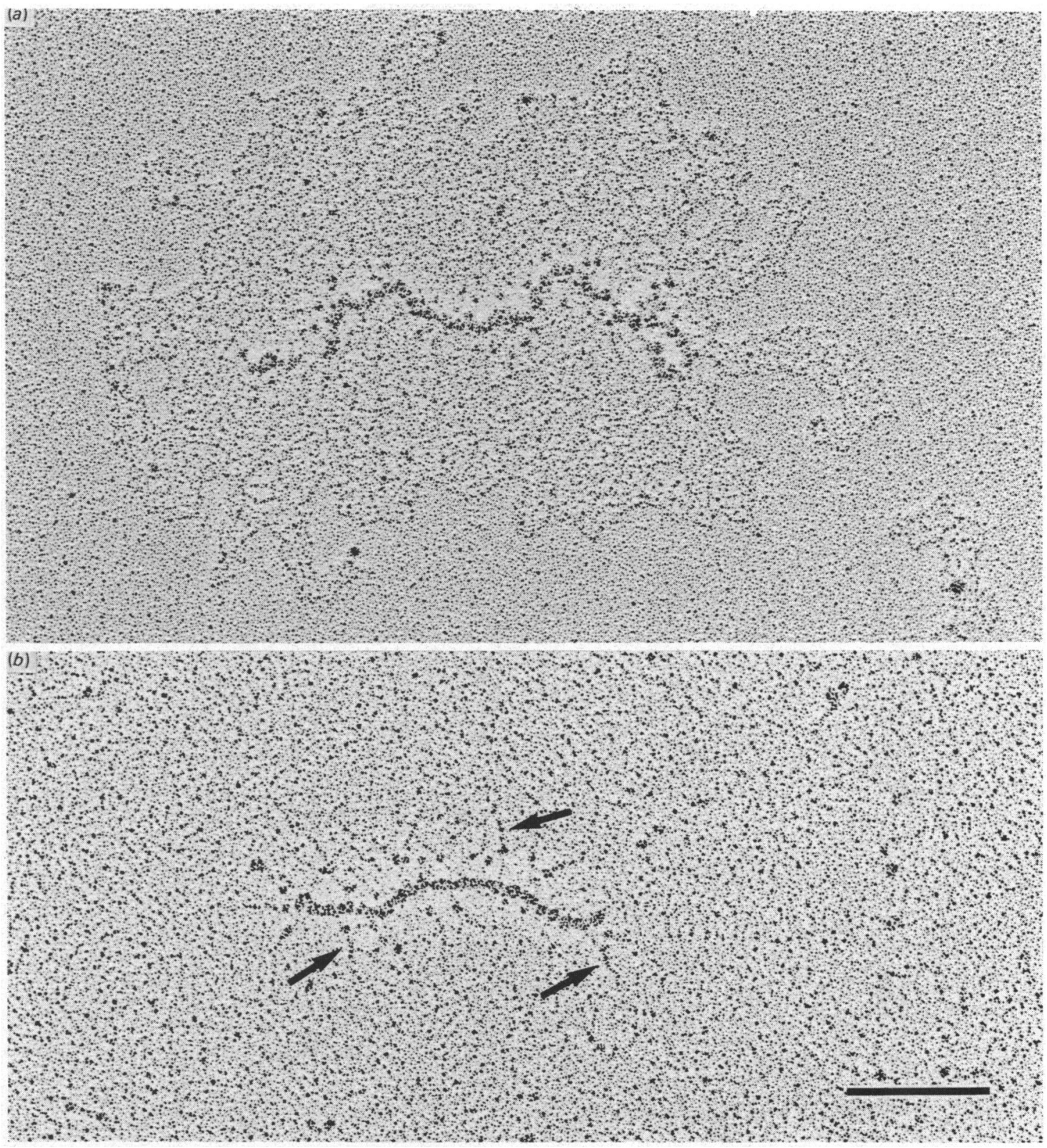

Fig. 7. Electron micrographs after rotary shadowing of reconstituted proteoglycan aggregates $(a)$ after spraying and $(b)$ by the micasandwich method

Molar proportions of hyaluronate segments to proteoglycan monomers to link protein are $0.33: 1: 3$. The bar represents $100 \mathrm{~nm}$.

at higher magnification. They demonstrate for a few particles the visualization of the extended protein domain E1 which connects the two globular domains G1 and G2 (see arrow in Fig. 5d). Furthermore, they reveal that $\mathrm{E} 1$ and the second globule are not involved in hyaluronate binding, either in the absence or in the presence of link protein. In most cases, however, El as well as free hyaluronate strands are invisible, as there is insufficient heavy metal available for the staining of thin structures in the surroundings of the globular protein moiety. Extended macromolecular complexes consisting of up to several hundred double globes attached to the hyaluronate binding, either in the absence or in the from less than $100 \mathrm{~nm}$ to several micrometres are frequently found.

\section{Reconstitution of complexes between chondroitinase- digested monomer and hyaluronate in the presence and in the absence of link protein}

The core protein was isolated by treatment of proteoglycan monomers from bovine nasal-septal cartilage with chondroitinase $\mathrm{ABC}$. For the reconstitution of link-free complexes, core-protein samples were combined with hyaluronate in $0.2 \mathrm{M}-\mathrm{NH}_{4} \mathrm{HCO}_{3}, \mathrm{pH}$ 7.9. Linkstabilized aggregates were prepared by dialysing coreprotein samples into dissociative conditions, adding hyaluronate and link protein and bringing the reaction mixtures back into associative conditions. After spraying and rotary shadowing, assembly products appeared as large extended structures. Fig. 6 shows some assembly 
products of core protein with hyaluronate (Fig. 6a), combined at molar ratios of hyaluronate $12 \mathrm{~nm}$ segment to core protein of $0.52: 1$, and a specimen of the same material at higher magnification (Fig. 6b). Fig. 6(c) demonstrates a link-stabilized aggregate formed at molar proportions of hyaluronate to core protein to link protein of $0.52: 1: 3$. Again the globular and extended protein domains are clearly revealed, as well as free strands of hyaluronate (arrowheads, in Fig. $6 a$ and $6 b$ ) at the end of some complexes. The protein-core domain organization within the individual complexes show conclusively that $\mathrm{G} 1$ is the only part of the protein core that binds to hyaluronate. In contrast, the other domains E1, G2, E2 and G3 (arrows in Fig. 6 b) point away from the central filament.

\section{Reconstitution of aggregates between proteoglycan monomers, hyaluronate and link protein}

Proteoglycan monomers were isolated from bovine nasal-septal cartilage by standard methods. Aggregates were:formed by adding hyaluronate and link protein to monomers under dissociative conditions and dialysing the samples into associative conditions. Specimens were prepared for electron microscopy either by conventional spraying or by the mica-sandwich technique (Mould et al., 1985). After rotary shadowing, proteoglycan aggregates as well as monomers appeared very similar to aggregates purified from cartilage extracts (Al fraction; Wiedemann et al., 1984). Fig. 7 shows selected aggregates after spraying (Fig. 7a) and mica-sandwich squeezing (Fig $7 b$ ). As in experiments with proteoglycan fragments, the heavily stained central filament can be seen in the centre of the aggregates, surrounded by a dense meshwork of protein cores and glycosaminoglycan chains pointing away from it. The aggregate in Fig. 7(a) was photographed in a zone at the border of the sprayed drop where proteoglycan monomers with partially collapsed glycosaminoglycan side chains can often be observed. For this reason it is impossible to trace individual core proteins or glycosaminoglycans, as can usually be done, but the border of the aggregate is well defined and of high contrast. Again, the globular domains G2 and G3 are clearly revealed and are not involved in the formation of the central filament. It is apparent that aggregates of whole proteoglycans have the same general organization as aggregates of fragments thereof. The electron micrograph Fig. $7(b)$, obtained by the mica-sandwich technique, shows the similar details of aggregate domain organization. Furthermore, the extended domain E1 and also a $90 \mathrm{~nm}$-long portion of the E2 domain are well resolved for some particles. This E2 piece is located distant to the globular domain G2 (arrows in Fig. 7b) and shows an apparent thickening, which might be explained by a collapse of the glycosaminoglycan side chains to the core protein. A region of similar morphological appearance and about $70 \mathrm{~nm}$ length has been previously described for proteoglycan aggregates on which the Kleinschmidt et al. (1962) technique had been applied (Heinegård et al., 1978).

\section{DISCUSSION}

Glycerol-spraying/rotary-shadowing electron microscopy was used for a detailed study of complexes formed by the interaction of proteoglycan fragments with hyaluronate in the presence and in the absence of link protein. It proved to be a powerful tool in the elucidation of the involvement in hyaluronate binding of the globular and extended core-protein domains of the large aggregating cartilage proteoglycan.

Electron microscopy after rotary shadowing of cartilage proteoglycan monomers and fragments combined with hyaluronate with and without link protein yields multimolecular complexes. It was not clear from previous rotary-shadowing images of proteoglycan aggregates (A1 fraction:Wiedemann et al., 1984) whether just one or both $\mathrm{N}$-terminal globular domains are involved in aggregate formation. Examination of aggregates in the present study has, however, clearly demonstrated that only G1 binds to hyaluronate, whereas G2 and the other extended and globular core-protein domains remain unbound. This is consistent with the structural differences between G1 and G2 suggested from immunochemical experiments (Hardingham et al., 1986), although major sequence homology is reported (Doege et al., 1987). However, on present evidence G2 is not directly involved in hyaluronate binding, nor has it apparently any function in the formation of link-stabilized aggregates. Furthermore, its keratan sulphate content is too low for it to be the keratan sulphate-rich peptide (Hardingham et al., 1986). Our own electron-microscopy results do not indicate a spacer function of $\mathrm{G} 2$, as the packing density of G1 on the central filament is approximately the same when complexes of hyaluronate with different proteoglycan fragments or proteoglycan monomers are compared. Instead, G2 may provide a proteolytic cleavage site during normal proteoglycan turnover on cartilage (Hardingham et al., 1986), or else it might be involved in interactions of proteoglycans with other components of the cartilage matrix. The functional significance of G3 also remains unknown. Its high abundance in some proteoglycan preperations suggests that this domain is an integral part of the molecule, rather than being just a precursor peptide. The homology with chick hepatic lectin seen in cDNA sequence data (Doege et al., 1986; Sai et al., 1986; Oldberg et al., 1987) indicates that G3 may be able to interact with other cartilage matrix components by having an affinity for carbohydrate sidechain constituents.

In the absence of link protein, the interaction of binding region G1 brings about the formation of a beaded-string structure. Binding is non-co-operative, and therefore the average distances between randomly bound G1 particles depend on the degree of saturation. Even at complete saturation, individual beads can still be distinguished. The minimum distance between them is $12 \mathrm{~nm}$. This distance was measured most accurately for isolated binding region, but minimum distances between the G1 domains of hyaluronate-bound double-globe fragments or protein cores are very similar. From the stoichiometry of link-free aggregates, composed of chondroitinase $\mathrm{ABC}$-digested core protein and hyaluronate, a value of 8-10 disaccharide units was derived under saturation conditions (Hascall \& Heinegård, 1974), and in similar experiments with binding region and hyaluronate 8 disaccharide units (Heinegård \& Hascall, 1974). This corresponds to $8-10 \mathrm{~nm}$ for a completely extended hyaluronate chain (Arnott \& Mitra, 1984). The fair agreement of this value with the electronmicroscopically measured distance is compatible with the concept that the hyaluronate that connects the G1 
domains in link-free aggregates is in extended conformation.

Link-stabilized aggregates of hyaluronate with binding region, double-globe fragment, protein core and intact proteoglycan monomers exhibit a central filament with a strikingly different structure. The filament has a wider diameter and a more condensed appearance. Futhermore, extended patches of protein-covered hyaluronate are formed, as contrasted with the random binding when link protein is absent. These features are the same after specimen preparation by spraying or the mica-sandwich technique, although the degree of spreading of the aggregates is distinctly different by the two techniques. In the present work aggregates were reconstituted from purified link protein, proteoglycan monomers and hyaluronate, but it follows from earlier studies (Wiedemann et al., 1984) that the central filament of aggregates formed from the entire Al fraction has a similar condensed appearance. Distances between individual G1 domains were no longer measurable in link-stabilized central filaments, and the condensed appearance of the central filament seen with the rotary-shadowing method indicates the presence of a continuous coat of protein along the hyaluronate strand. At least superficially, this observation is in contrast with the images obtained with the Kleinschmidt et al. (1962) method, where empty spaces are seen between individual proteoglycan monomers and where in early work spaces of average size 25-40 nm could be measured (Rosenberg et al., 1975; Heinegård et al., 1978). Those experiments were, however, performed under conditions where hyaluronate is likely to be in excess, whereas most of our experiments with link-stabilized central filaments were done with ratios of the protein components to hyaluronate ensuring binding close to saturation. Indeed, in work on calf and steer articular cartilage, where it is known that hyaluronate is difficult to extract quantitatively (Bayliss et al., 1983) and is probably present in extracts in sub-stoichiometric amounts ensuring saturation of re-formed aggregates, minimum values of about $18 \mathrm{~nm}$ for the spacing were obtained (Buckwalter et al., 1985). These values are closer to our minimum spacing of $12 \mathrm{~nm}$ for the binding region, and could reflect the same kind of continuous central-filament structure that we see at saturation. Also, the spreading in the presence of cytochrome $c$ performed in the Kleinschmidt et al. (1962) technique could result in stretching of the central filaments, giving somewhat higher values for the spacing with this method.

With a different experimental approach it was shown that, in reconstituted link-stabilized aggregates of rat chondrosarcoma proteoglycans, hyaluronate segments of an average size of 50 monosaccharides, i.e. $20-25 \mathrm{~nm}$ extended length, were protected from digestion with Streptomyces hyaluronidase (Faltz et al., 1979). This distance is, however, only the length to which the enzyme does not have access to the hyaluronate substrate, and may be longer than the minimum length occupied. Even so, as the enzyme did actually have access to the hyaluronate, these experiments could be taken as evidence against a continuous tight packing of proteins. It is, however, possible that the hyaluronate does make loop structures, occurring at regular intervals along the central filament, that are accessible to hyaluronidase. Even though the reasonable agreement between stoichiometric data on re-formed aggregates and the minimum spacing of $\mathrm{G1}$ domains of $12 \mathrm{~nm}$ could be taken as evidence for an extended conformation of hyaluronate in link-free aggregates, we do not have sufficient information to judge the degree of extension in the presence of link protein and binding region, and cannot exclude loops and other more complex hyaluronate structures, especially as only $50 \%$ of the added hyaluronate is accounted for in our experiments. The additional hyaluronate could be involved in higher-order structures not available for analysis, but could equally well have been lost to surfaces during preparation of samples. Such losses could also have affected the binding region, and especially the link protein, as we always had to add a molar excess of link protein to obtain link-stabilized central filaments.

The present results unequivocally show that the globular domain G1 is the only core-protein structure that participates in binding to hyaluronate, demonstrate that the binding of $\mathrm{Gl}$ alone to hyaluronate is nonco-operative and indicate the formation of a continuous protein structure in the central filament upon addition of link protein. This last observation can be taken as evidence for co-operativity of binding in the presence of link.

We gratefully acknowledge the skilful technical assistance of Mrs. Charlotte Fauser and the financial support of the Swiss National Science Foundation, the Maurice E. Müller Foundation, the Swedish Medical Research Council, Folksams Yrkeskadors Stiftelse, the Medical Research Council (U.K.) and the Arthritis and Rheumatism Council (U.K.).

\section{REFERENCES}

Arnott, S. \& Mitra, A. K. (1984) in Molecular Biophysics of the Extracellular Matrix (Arnott, S., Rees, D. \& Morris, E., eds.), pp. 41-67, Humana Press, New York

Bayliss, M. T., Venn, M., Maroudas, A. \& Ali, S. Y. (1983) Biochem. J. 209, 387-400

Bonnet, F., Dunham, D. G. \& Hardingham, T. E. (1985) Biochem. J. 228, 77-85

Buckwalter, J. A., Kuettner, K. E. \& Thonar, E. J.-M. (1985) J. Orthop. Res. 3, 251-257

Christner, J. E., Brown, M. L. \& Dziewiatkowski, D. D. (1978) Anal. Biochem. 90, 22-32

Cleland, R. L. (1979) Biochem. Biophys. Res. Commun. 87, 1140-1145

Doege, K., Fernandez, P., Hassell, J. R., Sasaki, M. \& Yamada, Y. (1986) J. Biol. Chem. 261, 8108-8111

Doege, K., Sasaki, M., Horigan, E., Hassell, J. R. \& Yamada, Y. (1987) J. Biol. Chem. 262, 17757-17767

Engel, J. \& Furthmayr, H. (1987) Methods Enzymol. 145, 3-78

Faltz, L. L., Caputo, C. B., Kimura, J. H., Schrode, J. \& Hascall, V. C. (1979) J. Biol. Chem. 254, 1381-1387

Franzén, A., Björnsson, S. \& Heinegård, D. (1981) Biochem. J. 197, 669-674

Hardingham, T. E. (1979) Biochem. J. 177, 237-247

Hardingham, T. E. (1986) in Rheumatology, vol. 10, Connective Tissue: Biological and Clinical Aspects (Kuhn, K. \& Krieg, T., eds.), pp. 143-183, S. Karger, Basel

Hardingham, T. E. \& Muir, H. (1972) Biochim. Biophys. Acta 279, 401-405

Hardingham, T. E., Beardmore-Gray, M., Dunham, D. \& Ratcliffe, A. (1986) Ciba Found Symp. 124, 30-46

Hascall, V. C. \& Heinegård, D. (1974) J. Biol. Chem. 249, $4242-4249$

Hascall, V. C. \& Sajdera, S. W. (1970) J. Biol. Chem. 245, $4920-4930$ 
Heinegård, D. \& Axelsson, ' I. (1977) J. Biol. Chem. 252, 1971-1979

Heinegård, D. \& Hascall, V. C. (1974) J. Biol. Chem. 249, $4250-4256$

Heinegård, D. \& Paulsson, M. (1984) in Extracellular Matrix Biochemistry (Piez, K. \& Reddi, A., eds.), pp. 277-328, Elsevier, New York

Heinegård, D., Lohmander, S. \& Thyberg, J. (1978) Biochem. J. 175, 913-919

Heinegård, D., Wieslander, J., Sheehan, J., Paulsson, M. \& Sommarin, Y. (1985) Biochem. J. 225, 95-106

Heinegård, D., Franzén, A., Hedbom, E. \& Sommarin, Y. (1986) Ciba Found. Symp 124, 69-82,

Kleinschmidt, A. K., Lang, D., Jackerts, D., \& Zahn, R. K. (1962) Biochim. Biophys. Acta 61, 857-864

Lohmander, S., DeLuca, S., Nilsson, B., Hascall, V. C., Caputo, C. B., Kimura, J. H. \& Heinegård, D. (1980) J. Biol Chem. 255, 6084-6091

McGhee, J. D. \& Von Hippel, P. H. (1974) J. Mol. Biol. 86, 469-489

Mould, P., Holmes, D., Kadler, K. \& Chapman, J. (1985) J. Ultrastruct. Res. 91, 66-76

Recieved 30 October 1987/18 January 1988; accepted 17 March 1988
Nieduszynski, I. A. \& Sheehan, J. K. (1981) Biochem. Soc. Trans. 9, 502-504

Nieduszynski, I. A., Sheehan, J. K., Phelps, C. F., Hardingham, T. E. \& Muir, H. (1980) Biochem. J. 185, 107-114

Oldberg, A.., Antonsson, P. \& Heinegård, D. (1987) Biochem. J. 243, 255-259

Paulsson, M., Mörgelin, M., Wiedemann, H., BeardmoreGray, M., Dunham, D., Hardingham, T. E., Heinegård, D., Timpl, R. \& Engel, J. (1987) Biochem. J. 245, 763-772

Rosenberg, L., Hellmann, W. \& Kleinschmidt, A. (1970) J. Biol. Chem. 245, 4123-4130

Rosenberg, L., Hellmann, W. \& Kleinschmidt, A. (1975) J. Biol. Chem. 250, 1877-1883

Sai, S., Tamaka, T., Kosher, R. A. \& Tanzer, M. L. (1986) Proc. Natl. Acad. Sci. U.S.A. 83, 5081-5085

Shotton, D. M., Burke, B. \& Branton, D. (1979) J. Mol. Biol. 131, 303-329

Tengblad, A. (1981) Biochem. J. 199, 297-305

Wellauer, P., Wyler, T. \& Buddecke, E. (1972) Hoppe-Seyler's Z. Physiol. Chem. 353, 1043-1052

Wiedemann, H., Paulsson, M., Timpl, R., Engel, J. \& Heinegård, D. (1984) Biochem. J. 224, 331-333 